OPEN ACCESS

Edited by:

James Ko,

The Education University of Hong Kong, Hong Kong SAR,

China

Reviewed by:

Christoph Helm,

University of Teacher Education Zug,

Switzerland

Karien Dekker,

RMIT University, Australia

*Correspondence:

Kim H. R. Ouwehand ouwehand@essb.eur.n

Specialty section:

This article was submitted to Educational Psychology, a section of the journal

Frontiers in Education

Received: 15 November 2021 Accepted: 02 February 2022

Published: 08 March 2022

Citation:

Ouwehand KHR, Xu KM, Meeuwisse $M$, Severiens SE and Wijnia L (2022) Impact of School

Population Composition, Workload, and Teachers' Utility Values on Teaching Quality: Insights From the Dutch TALIS-2018 Data.

Front. Educ. 7:815795.

doi: 10.3389/feduc.2022.815795

\section{Impact of School Population Composition, Workload, and Teachers' Utility Values on Teaching Quality: Insights From the Dutch TALIS-2018 Data}

\author{
Kim H. R. Ouwehand ${ }^{1 *}$, Kate M. X ${ }^{2}$, Marieke Meeuwisse ${ }^{1}$, Sabine E. Severiens ${ }^{1}$ and \\ Lisette Wijnia ${ }^{2}$
}

${ }^{1}$ Department of Psychology, Education and Child Studies, Erasmus School of Social and Behavioral Sciences, Erasmus University Rotterdam, Rotterdam, Netherlands, ${ }^{2}$ Department of Conditions for Lifelong Learning, Faculty of Educational Sciences, Open Universiteit Nederland, Heerlen, Netherlands

Several studies show that teaching quality is an important predictor of students' academic achievement. However, less is known about factors that are important for teaching quality. In the present study, it was hypothesized that school population composition [i.e., students' socioeconomic status (SES) and migration background], workload, and teachers' utility values toward teaching would be important factors related to their teaching quality. The Dutch Teaching and Learning International Survey (TALIS) 2018 was explored ( $N=1,884$, secondary school teachers and 116 school leaders) to test our hypotheses. Data gathering followed a two-step procedure. Firstly, 200 schools were randomly selected. Secondly, 20 teachers within each school were randomly selected. Multi-item scales operationalized teaching quality on teachers' self-reported classroom management, cognitive activation, clarity of instruction, and positive student-teacher relationships. Multilevel analyses showed that teachers' social utility value was positively associated with all dimensions of teaching quality, whereas personal utility value was only associated with classroom management and clarity of instruction. Teachers working at schools with moderate shares of students from a socioeconomically disadvantaged background reported higher clarity of instruction ( $\beta=0.42)$, and moderate and high shares report lower cognitive activation $(\beta=-0.40$, $\beta=-0.33$, respectively) than those working at schools with low shares. Student-teacher relationships were rated more positively by teachers working at schools that reported no students with a migrant background than those working at schools with a small share $(\beta=0.33)$. Moreover, teachers working at schools with high shares of students with migration backgrounds ( $\beta=-0.17$ ) reported more negative relationships. These results suggest that dealing with low-SES students at schools affects the cognitively-focused elements of teaching quality, while dealing with students with a migration background seems to affect the social teaching qualities of teachers.

Keywords: SES, migration background, classroom management, cognitive activation, clarity of instruction, student-teacher relationship 


\section{INTRODUCTION}

High-quality education is crucial in our modern society. School effectiveness, often determined by students' performance attainments at the end of schooling, can be studied using the Context-Input-Process-Outcome (CIPO) model (Scheerens, 1990, 2000). According to this framework, the output of education, such as students' achievement, cannot be studied in isolation from input and process variables within a particular context. Input variables can consist of student, classroom, or teacher characteristics and financial and material aids in a school (Scheerens, 2000; Klieme, 2013). The transformation process between input variables and the output of schooling consists of the factors that make it possible for students to learn, such as instructional methods and curriculum decisions. Because teachers are at the center of the learning materials and the students, they are key figures in promoting students' motivation and achievement (e.g., Wentzel, 2009). Indeed, research shows that teaching quality is crucial for students' academic achievement (e.g., Baumert et al., 2010; Higgins et al., 2014; Gustafsson et al., 2018) and motivation (Maulana et al., 2016; Aelterman et al., 2019). Therefore, teaching quality can be considered a critical process variable within the CIPO model (Klieme, 2013).

Teaching quality is a multidimensional construct (Lazarides et al., 2021). Klieme et al. (2009) and Fauth et al. (2019) identified three dimensions of teaching quality: classroom management, cognitive activation, and supportive climate. Classroom management involves coping with disruptive behaviors, expressing and implementing classroom rules and procedures, and smooth transitions. Effective classroom management is considered a precondition for effective teaching and learning (Jones and Jones, 2012). Classroom management interventions have been associated with various adaptive student outcomes, such as academic achievement and time-on-task (Korpershoek et al., 2016). Cognitive activation concerns the use of challenging tasks and practices that aim to foster students' cognitive engagement, such as discussions and student activation, and has been positively associated with academic achievement (Fauth et al., 2019). The third teaching quality dimension, supportive climate, consists of a student-oriented affective and a cognitive component (Klieme et al., 2009; Lazarides et al., 2021). The affective component concerns positive student-teacher relations that are warm, caring, and emotionally supportive (Fauth et al., 2019; Lazarides et al., 2021). The cognitive component concerns the clarity of instruction. It refers to a teacher's ability to explain content clearly to students, such as setting clear goals and expectations and making connections with prior knowledge (Organisation for Economic Co-Operation and Development [OECD], 2019; Lazarides et al., 2021). Fauth et al. (2019) showed that the teaching quality dimension supportive climate was positively associated with students' interest.

Because teaching quality dimensions are conditional for learning and have been associated with positive student outcomes, it is crucial to investigate which school and teacher factors affect teaching quality. Therefore, in this study, we examined the effect of teachers' utility values, workload, and school population composition on teaching quality. Teaching quality was defined by the four components described above: classroom management, cognitive activation, clarity of instruction (i.e., the cognitive component of supportive climate), and positive student-teacher relations (i.e., the affective dimension of supportive climate; Klieme et al., 2009; Fauth et al., 2019; Lazarides et al., 2021). All these components are assessed by the Dutch Teaching and Learning International Survey (TALIS) 2018 dataset, consisting of 1884 secondary school teachers and 116 schools. TALIS is a reoccurring international survey organized by the OECD and has been set out in 2008, 2013, and 2018. The next round is planned for 2024. For TALIS 2018, 260,000 teachers and 15,000 school leaders participated, representing 48 countries and economies. In separate surveys, teachers and school leaders rate their perceptions on work-related constructs such as professional development, teaching beliefs, practices, work assessment, job satisfaction, needs, workload, leadership, work climate, and school population composition (Organisation for Economic Co-Operation and Development [OECD], 2019).

\section{School Population Composition}

School population composition is considered as an input variable in our model. The school population composition, such as the share of students with a low socioeconomic status (SES) and migration backgrounds of its students, could impact teaching quality. For the TALIS, migration background was defined by being born in another country or having parents born in another country. Important to mention is that SES and migration background overlap as immigrants or people with a (non-western) migration background have relatively low SES when compared to people without a (nonwestern) migration background (Geerlings et al., 2018). However, studies show that effects of SES and migration background can be disentangled for some teaching quality characteristics. For example, Rjosk et al. (2014) showed that teachers tend to decrease cognitive activation (i.e., challenging students' thinking) when teaching in classrooms with a high number of students coming from low-SES backgrounds (regardless of whether they were from a language minority background). It was also found that teachers perceive high SES students as more teachable than low-SES students, even when cognitive abilities are equal (Agirdag, 2018). Furthermore, schools with a relatively high amount of low-SES students also spend less instruction time on challenging domains, such as science (Willms, 2010). These studies suggest that a higher share of low-SES students at a school is related to lower quality and quantity of instruction.

In the Netherlands, the cultural diversity of the population has increased massively; the population with an immigrant status or migrant background has grown from $9.2 \%$ in 1972 (Jennissen et al., 2018) to $24.8 \%$ in 2020 (Centraal Bureau voor de Statistiek [CBS], 2020). More culturally diverse schools and classrooms have emerged with this increase, which can be challenging for Dutch teachers (for an overview of the Dutch educational system, 
see Nuffic, n.d.). ${ }^{1}$ In a multicultural classroom, teachers need to be aware of the different factors that influence classroom life and need to address the needs and interests of students with different backgrounds (Wubbels et al., 2006; Patall and Zambrano, 2019). Therefore, a multicultural classroom requests higher levels of teaching quality than homogenous classrooms (Wubbels et al., 2006; Severiens et al., 2014; Archambault et al., 2020). Wubbels et al. (2006) identified four competencies teachers need in multicultural classrooms: (a) Monitoring and managing student behavior, (b) creating positive student-teacher relationships, (c) teaching for student attention and engagement, and (d) required teacher attitudes and knowledge. These competencies align with generic teaching quality dimensions (Wubbels et al., 2006; Severiens et al., 2014). For example, monitoring and managing student behavior is similar to classroom management (Klieme et al., 2009). The competence creating positive student-teacher relationships concerns monitoring the needs of their students, showing respect for and interest in the students and their background (Wubbels et al., 2006), and aligns with the cognitive and affective dimensions of supportive climate (Lazarides et al., 2021). The third competence, teaching for student engagement and attention, concerns stimulating all students to participate and relies on cognitive activation (Severiens et al., 2014). The fourth component, having the required attitudes and knowledge, means that teachers need to be aware of their own normative behavior, their perceptions of students, and the position of students within their class (Wubbels et al., 2006). This last component is not included in the conceptualizations of teaching quality by Klieme et al. (2009). Drawing further on this fourth competence, Tielman et al. (2021) stressed the tension field between the normative values of teachers and that of pupils in culturally diverse classes "Teachers sometimes find themselves in a struggle between their own values and changing value systems in society on the one hand, and at the same time their wish to let students develop their own value orientations" (p. 3). Tielman et al. (2021) concluded that student-teacher relationships based on trust and a pleasant social climate could decrease these tensions between teachers and students. This study underscores the importance of establishing a supportive climate with positive student-teacher relationships. However, in this respect, it is problematic that the share of teachers with a migration background in the Netherlands is small relative to the number of students with a migration background, especially those with a non-western background (Centraal Bureau voor de Statistiek [CBS], 2020). Thijs et al. (2012) showed that ethnic-Dutch teachers evaluated their relationship quality with Moroccan-Dutch students as less favorable than with ethnic-Dutch and Turkish-Dutch students. This suggests

\footnotetext{
${ }^{1}$ In order to be able to contextualize the situation in the Netherlands, it is important to consider two specific aspects of the Dutch education system. The Dutch school system is a public school system, almost all Dutch schools are funded and monitored by the government. At the age of 12, Dutch pupils transition to one of three tracks in secondary education. Test scores in combination with a school advice, leads to either the vocational track ( 4 years), a general track ( 5 years) or a pre-university track (6 years; see also Nuffic, n.d.). Parents' SES play a large role in this advice, which impacts school composition in secondary education: the vocational track generally contains larger percentages of students from low-SES and migration backgrounds.
}

that ethnic incongruence between the teacher and student could affect the student-teacher relationship. Unfortunately, the TALIS did not ask teachers about their own migration or ethnic background, so no hypotheses on this could be tested in the current study.

From the research findings described above, it is expected that low SES and migration background might have similar effects but also unique effects on teaching quality. Because prior research revealed that in low-SES schools, less cognitive activation took place (Rjosk et al., 2014) and less time was spent on challenging topics (Willms, 2010), we, in particular, expected a negative effect of low SES on cognitive activation (H1). In addition, low-SES students are perceived as less teachable (Agirdag, 2018). This might lead teachers to try and compensate for their students' perceived lower cognitive abilities by increasing the clarity of instruction. Therefore, we expected higher clarity of instruction for low-SES schools (H2). From the negative impact of ethnic discrepancy between teacher and students (Thijs et al., 2012) with a dominantly white teacher population in the Netherlands (Traag, 2018) we expect more negative ratings on the student-teacher relationships for teachers working in schools with high shares of students with migration backgrounds (H3). As relational aspects between the students in ethnic diverse classrooms are tense (e.g., Tielman et al., 2021), teachers in classrooms with a higher share of students with a migration background pay more attention to classroom management (H4).

\section{Workload}

Another input variable in our model that could affect teaching quality is the experienced workload (Dube-Xaba and Makae, 2022). Workload concerns all activities teachers need to spend on their official duties during or after school hours (Johari et al., 2018). High psychological demands (Harmsen et al., 2019) and workload (Den Brok et al., 2017) are significant predictors for the attrition of teachers in the Netherlands, a country facing a serious teacher shortage already (Vereninging van Scholen in het Voortgezet Onderwijs [VO RAAD], n.d.). A study from the neighboring country Flanders, Belgium, by Amitai and Van Houtte (2022) showed that novice teachers' workload and feeling unprepared to manage diverse classrooms were reasons to leave the profession of teaching. However, well-performing teachers are less likely to quit their jobs (Krieg, 2006). Also, the supposed negative impact of workload on educational quality has been a popular item in the Dutch press (e.g., Chaudron and Dujardin, 2019). Workload is negatively associated with teachers' selfratings of their performance and job satisfaction (Huyghebaert et al., 2018), which could, in turn, negatively affect their teaching quality. Therefore, it was hypothesized that workload negatively affects all teaching quality outcome variables (H5).

\section{Motivation: Utility Values}

A teacher's motivation to choose teaching as a career is another input variable that could affect teaching quality. Personal and social utility values were introduced by Watt and Richardson (2007) to investigate teachers' motivations to enter the profession in a system called the Factors Influencing Teaching Choice (FITChoice). The FIT-Choice model is based on expectancy-value 
theory. A distinction is made between primary motivational beliefs for teaching (e.g., abilities to teach effectively) and three subjective task values: intrinsic value, personal utility value, and social utility value (Richardson and Watt, 2014). Intrinsic value refers to a teachers' interest in teaching. Personal utility value concerns the motivation for practical and attractive aspects of teaching, such as having a steady job with fixed hours and a pension plan that fits well with the teachers' personal life (e.g., time for family; Watt and Richardson, 2007). In contrast, social utility value represents more altruistic motivation, such as contributing to society, shaping young students' future, and enhancing social equity (Watt and Richardson, 2007, 2012; Richardson and Watt, 2014).

In our study, we were interested in the effect of teachers' subjective task values on teaching quality. In the TALIS, only personal and social utility values were measured (Organisation for Economic Co-Operation and Development [OECD], 2019). Social utility value is considered an adaptive motivation for teaching (Richardson and Watt, 2014). Research shows that social utility values have been associated with pre-service teachers' interest in the profession (Giersch, 2016), planned persistence to become a teacher, and retention (O'Brien and Schillaci, 2002; Bruinsma and Jansen, 2010; Richardson and Watt, 2014). There is some evidence that social utility value is positively associated with teaching quality. Research showed that social utility value was directly associated with better student-teacher relationships and certain aspects of classroom management (Berger and Girardet, 2021). Moreover, Richardson and Watt (2014) found that social utility value predicted later positive teaching behaviors (e.g., positive expectations, student-teacher relationships, and clear structure/expectations) through planned persistence. Furthermore, with qualitative interviews, Parr et al. (2021) found links between social utility value and favorable instructional practices such as challenging students to think critically and centering instruction on students' needs. Therefore, we expected that social utility value is positively associated with all teaching quality dimensions (H6).

In contrast to social utility values, research showed more mixed findings for personal utility values. For example, König and Rothland (2012) found a negative association between "job security" motives with pedagogical knowledge of pre-service teachers on a first measurement, but a positive effect on learning gain over the course of 1 year. In contrast, Girardet and Berger (2018) showed that teachers with personal utility values showed a less adaptive change in classroom management style focusing on structure after a teacher education program. Positive associations of personal utility values have been found with career interest (Giersch, 2016) and job satisfaction (Liu et al., 2020). However, Richardson and Watt (2014) found that personal utility value was not associated with planned persistence and positive and negative teaching behaviors. Due to the mixed effects of prior research, we expected that personal utility would either be unassociated with teaching quality dimensions or would show small, positive associations (H7). However, we did not expect a negative effect on teaching quality.

As mentioned, personal utility values concern the practical and attractive aspects of teaching as a reason for entering a teaching career, such as work-life balance and job security (Watt and Richardson, 2007). A higher workload could impact the actual benefits a teacher reaps from having a teaching career. Increased workload means the job could affect the time available for private life (cf. Johari et al., 2018). It was hypothesized that workload moderates the relationship between personal utility value on teaching quality. Specifically, we expected that high workload combined with high personal utility value could negatively affect teaching quality (H8). No such moderating effect of workload is expected on the association between social utility value and teaching quality (9).

\section{Cross-Level Interactions}

The hypothesized relationships between workload and utility values, on the one hand, and teaching quality, on the other hand, may differ in schools that vary according to composition. In other words, we may find cross-level interactions. The reason is that schools with large shares of students from low SES and migration backgrounds more often deal with problems such as high rates of teacher dropout in combination with a relatively high number of social problems among their students (Payne, 2014). Moreover, teacher self-efficacy is often lower in these schools (Parkhouse et al., 2019). Teachers in these schools may have high personal and social utility values. However, in a context of low teacher retention combined with low levels of teacher selfefficacy, teachers' high utility values may not translate as easily into an orderly classroom climate, clear instruction, and good quality student-teacher relationships.

It is also not unthinkable that a relatively high workload in classrooms with high shares of students from low SES and migration backgrounds makes it even harder to establish good teaching quality. Or conversely, in urban schools that manage to keep workload relatively low, it may be possible to deliver good quality instruction, good classroom management, studentteacher relationships, and cognitive activation. Based on these lines of reasoning, we arrive at two hypotheses with regard to cross-level interactions. Firstly, in classrooms with relatively low shares of low-SES students and (or) students from migration backgrounds, we expected utility values to affect teaching quality positively. In contrast, this relation might be less pronounced in classrooms with relatively high percentages of low-SES students and (or) students from migration backgrounds (H10). Secondly, we expected a negative relationship between workload and teaching quality in classrooms with relatively high percentages of low-SES students and (or) students from migration backgrounds. In contrast, this relationship could be less pronounced in classrooms with relatively low shares of low SES-students and (or) students from migration backgrounds (Hypothesis 11).

\section{Hypotheses of the Present Study}

Below we provide an overview of all hypotheses specified and argued for in the introduction:

H1: Lower cognitive activation at low-SES schools.

$\mathrm{H} 2$ : Higher clarity of instruction at low-SES schools. 
H3: Lower quality of student-teacher relationships at schools with high shares of students with a migration background.

H4: Higher classroom management skills at schools with high shares of students with a migration background.

H5: Negative effect of workload on all teaching quality outcome variables.

H6: Positive effect of social utility and all teaching qualities.

H7: No (or small) effects of personal utility values on teaching quality.

H8: Workload moderates relation between personal utility and teaching quality.

H9: No moderation effect of workload on the relation between social utility and teaching quality.

H10: In classrooms with relatively low shares of lowSES students and (or) students from migration backgrounds, both utility values have a positive effect on teaching quality.

H11: In classrooms with relatively high shares of low-SES students and (or) students from migration backgrounds, there is a negative relation between workload and teaching quality.

\section{MATERIALS AND METHODS}

\section{Participants}

In total, 1884 secondary school teachers $(54 \%$ male $)$ and 125 school leaders $(62 \%$ male) from 116 schools participated in the Dutch TALIS 2018 (Sapulete et al., 2018). Teachers' age ranged between 19 and 71 years, with $M_{\text {age }}=42.8$ years, $S D_{\text {age }}=11.85$. School leaders' age ranged between 32 and 68 years, with $M_{\text {age }}=53.9$ years, $S D=7.76$. Response rates were $76 \%$ among teachers and $80 \%$ among school leaders.

\section{Procedure}

Data gathering followed a two-step procedure. Firstly, 200 schools were randomly selected. Secondly, 20 teachers within each school were randomly selected (see TALIS 2018, Technical Report for a detailed description; Organisation for Economic Co-Operation and Development [OECD], 2019). To be included in the analysis of TALIS 2018, at least $50 \%$ of teachers within each selected school had to participate. The teacher and school leader surveys were administered between March and July 2018 (for more information, see Organisation for Economic Co-Operation and Development [OECD], 2019).

\section{Variables}

Below, we describe the (sub)scales used in this study and their abbreviated names in the dataset (see TALIS 2018 technical report; Organisation for Economic Co-Operation and Development [OECD], 2019). Reliability is indicated by Cronbachs alpha $(\alpha)$ for sets of items with tau-equivalence (all the items have equal covariance with the true score), and omega coefficients when tau-equivalence was violated (see Deng and Chan, 2017).

\section{Level 2 (School Level) Independent Variables}

The shares of students from a socioeconomically disadvantaged background (SES) and students with an immigrant status or migration background (MIGR) were based on the principals' ratings on a five-point Likert scale $(1=$ none, $2=1-10 \%, 3=11$ $30 \%$, and $4=31-60 \%$, or $5 \geq 60 \%$ ). With two separate items, principals were asked to estimate the share of (1) students from socioeconomically disadvantaged families and (2) those with an immigrant status or migration background. They received short defining descriptions on both terms. Socioeconomically disadvantaged families were described as unprivileged families that need help (social services, help organizations) to fulfill their basic needs, such as shelter, food and health care. An immigrant student was described as a student that is born abroad and students with a migration background as having parents who are born abroad.

The ratings on SES and migration background were converted into dummies, with the largest category being the reference group. The majority of schools reported having 1-10\% students of low-SES backgrounds and 1-10\% students with a migration background. Therefore, for both SES and MIGR, the reference group was $1-10 \%$ students. For SES, two dummies were created. The first dummy, SES1, contrasted the reference group with schools with 11-30\% low-SES students, and the second dummy, SES2, contrasted the reference group with schools with $31-60 \%$ and $>60 \%$ low-SES students. These two final categories were piled together because the $>60 \%$ category contained only one school with 11 teachers. No schools were reported to be without students from lowSES backgrounds.

For migration background, three dummies were created. Nine schools reported having no students with a migration background. MIGR0 contrasted the reference group (1-10\% migration background) with schools without immigrant status or migration background students. MIGR1 contrasted the reference group with schools reporting $11-30 \%$ of students with immigrant status or migration backgrounds. Finally, MIGR2 contrasted the reference group with schools reporting 31-60\% and $>60 \%$ of students with immigrant status or migration background. These two final categories were piled together because the $>60 \%$ category contained only one school with 11 teachers (see Table 1 for the frequencies of SES and Migration per category).

\section{Level 1 (Teacher Level) Independent Variables}

Social utility value was composed of three items $(\alpha=0.78)$, personal utility value by four items $(\alpha=0.93)$, and workload by five items $(\alpha=0.74)$. In the analysis, social utility value, personal utility value, and workload were centered around the grand mean (see Appendix for all the items).

\section{Dependent Variables: Teaching Quality}

Classroom management ( $\alpha=0.89)$, cognitive activation ( $\alpha=0.79)$, clarity of instruction $(\alpha=0.74)$, and student-teacher 
TABLE 1 | Distribution of schools reporting low to high shares of students with socioeconomically disadvantaged (SES) backgrounds and (or) immigrant status or migration backgrounds (MIGR).

\begin{tabular}{|c|c|c|c|c|c|c|c|c|}
\hline \multirow[b]{3}{*}{ Category } & \multicolumn{4}{|c|}{ SES } & \multicolumn{4}{|c|}{ MIGR } \\
\hline & \multicolumn{2}{|c|}{ Schools } & \multicolumn{2}{|c|}{ Teachers } & \multicolumn{2}{|c|}{ Schools } & \multicolumn{2}{|c|}{ Teachers } \\
\hline & Number & $\%$ & Number & $\%$ & Number & $\%$ & Number & $\%$ \\
\hline $0 \%$ & 0 & 0 & 0 & & 9 & 7.1 & 136 & 7.2 \\
\hline $1-10 \%$ & 74 & 58.3 & 1,088 & 57.7 & 86 & 67.7 & 1,327 & 70.4 \\
\hline $11-30 \%$ & 35 & 27.6 & 559 & 29.7 & 17 & 13.4 & 261 & 13.9 \\
\hline $31-60 \%$ & 8 & 6.3 & 118 & 6.3 & 5 & 3.9 & 41 & 2.2 \\
\hline$>60 \%$ & 1 & 0.8 & 11 & 0.6 & 1 & 0.8 & 11 & 0.6 \\
\hline \multirow[t]{2}{*}{ Missing } & 9 & 7.1 & 108 & 5.7 & 9 & 7.1 & 108 & 5.7 \\
\hline & 127 & 100 & 1,884 & 100 & 127 & 100 & 1,884 & 100 \\
\hline
\end{tabular}

relationships ( $\Omega=0.81$ ) were each composed by four items (see Appendix).

\section{Analyses}

Firstly, it was tested whether multilevel modeling would be preferred over a unilevel approach. This was done by comparing a null model (in which we fixed variances between clusters to zero) to an independence model in which variances within and between clusters are accounted for. We used a Chi-square test of the deviance as a fit measure for our modeling, with a cutoff of $\Delta-2 \mathrm{LL} / \mathrm{df}>3.84$ (which is the "95\% critical value for a squared normal deviate for only one cell"; Breslow and Day, 1987, p. 130). As shown in Table 2, the independence model has a significantly better fit than the null model in which the variance between clusters is fixed (i.e., not accounted for). We also added the AIC and BIC to Table 2 as model fit indices.

Secondly, we inspected the correlations between all independent and dependent variables (see Table 3). Two multivariate multilevel analyses using Mplus 8 were conducted. The first analyses tested the relations and possible crosslevel interactions between social and personal utility value, workload, SES, and migration levels on classroom management, cognitive activation, clarity of instruction, and student-teacher relationships. It was assessed whether it would be valid to test for cross-level interactions using random slopes for the lower-level variables. This method reduces Type II errors and therefore is a strict approach to test for cross-level interactions (for an elaborate argumentation and statistical support of this method, see Heisig and Schaeffer, 2019). The second analysis tested whether workload moderated the relationship between utility values (social and personal) and classroom management, cognitive activation, clarity of instruction, and student-teacher relationships.

\section{RESULTS}

First, the results of the correlational analyses that are relevant to our hypotheses are described, followed by the multivariate multilevel regression model and moderation model testing the hypotheses. As an index for effect size, standardized $\beta$ will be given for the significant results reported. All significant results regarding the correlations and hypotheses will be reported in the text for readability. All statistics can be found in Tables $\mathbf{2}$ and $\mathbf{3}$.

SES was positively correlated with social utility value, and clarity of instruction, indicating that teachers working at schools with more students from socioeconomically disadvantaged backgrounds reported higher levels of social utility value and spent more time on clarity of instruction. Migration background correlated positively with social and personal utility value and negatively with student-teacher relationships. This finding indicates that teachers working at schools with higher numbers of students with a migration background reported higher levels of social and personal utility value and rated the relationship with their students more negatively. Furthermore, personal utility value was positively associated with workload, classroom management, and clarity of instruction.

In support of H1, the multilevel regression model, the SES1 and SES2 contrasts yielded negative coefficients for cognitive activation, $\beta=-0.40$ and $\beta=-0.33$, respectively. This indicates that teachers at schools with a moderate and high compared to a low share of low-SES students spend less time and attention on challenging and activating teaching. In support of $\mathrm{H} 2$, the results revealed that the SES1 contrast was positively related to clarity of instruction, $\beta=0.42$. This indicates that teachers at schools with a moderate share of low-SES students reported spending more time and attention on clarity of instruction than those teaching at schools with a low share of low-SES students.

In support of H3, the MIGR0 contrast showed that teachers at schools reporting to have no students with a migration background report a more positive student-teacher relationship than those working in schools with a moderate share of students with a migration background $\beta=0.33$. The MIGR2 contrast showed that teachers working at schools with a high share of students with a migration background reported a more negative student-teacher relationship quality than those working at schools without students with a migration background, $\beta=-$ 0.17 . In contrast to our expectations (H4), no effect on classroom management was found.

Next, the relations between the independent Level 1 (variables workload, social and personal utility values) and the outcome variables (classroom management, cognitive activation, clarity 
TABLE 2 | Multivariate multilevel model testing social and personal utility values (SUV and PUV), workload (WL) and school population characteristics (SES and MIGR) on teaching quality: Clarity of instruction (Cl), classroom management (CM), cognitive activation (CA) and student-teacher relationships (STR).

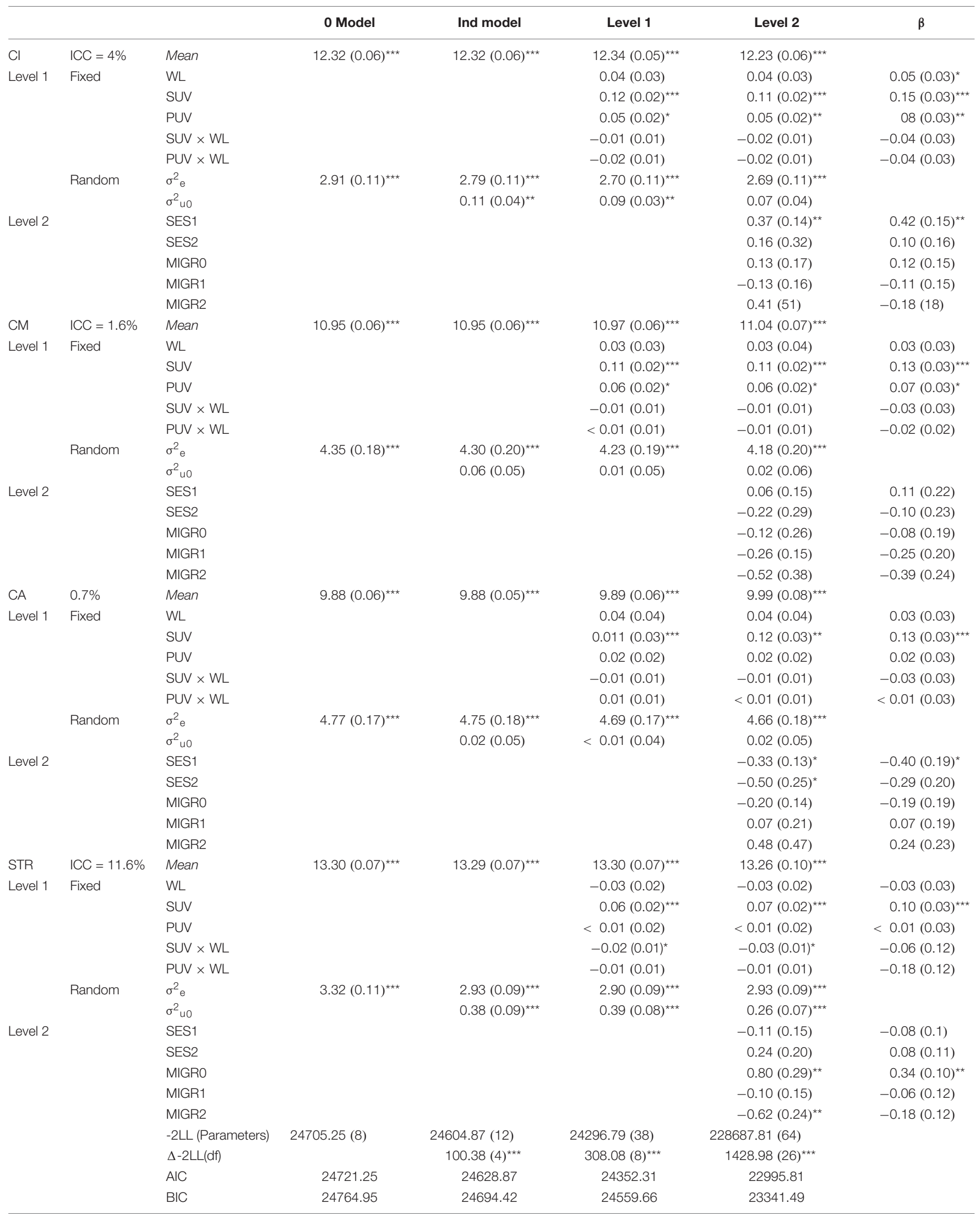

*significance at the level of $p<0.05$, **significance at the level of $p<0.01$, and *** significance at the level of $p<0.001$. 
TABLE 3 | Correlations between the variables.

\begin{tabular}{|c|c|c|c|c|c|c|c|c|c|}
\hline & $N$ & MIGR & $\begin{array}{l}\text { Social utility } \\
\text { value }\end{array}$ & $\begin{array}{c}\text { Personal } \\
\text { utility value }\end{array}$ & Workload & $\begin{array}{l}\text { Classroom } \\
\text { management }\end{array}$ & $\begin{array}{l}\text { Cognitive } \\
\text { activation }\end{array}$ & $\begin{array}{c}\text { Clarity of } \\
\text { instruction }\end{array}$ & $\begin{array}{l}\text { Student-teacher } \\
\text { relationship }\end{array}$ \\
\hline SES & 1,776 & $0.48^{\star \star \star}$ & $0.12^{\star \star \star}$ & 0.04 & -0.04 & -0.01 & -0.05 & $0.08^{\star \star}$ & -0.03 \\
\hline MIGR & 1,776 & - & $0.05^{\star}$ & $0.06^{*}$ & -0.02 & -0.02 & 0.01 & 0.01 & $-0.10^{\star \star \star}$ \\
\hline Social utility value & 1,874 & & - & $0.05^{\star}$ & 0.02 & $0.13^{\star \star \star}$ & $0.12^{\star \star \star}$ & $0.18^{\star \star \star}$ & $0.07^{\star \star}$ \\
\hline Personal utility value & 1,873 & & & - & $0.09^{\star \star \star}$ & $0.08^{\star \star}$ & 0.03 & $0.08^{\star \star}$ & -0.01 \\
\hline Workload & 1,588 & & & & - & 0.04 & 0.04 & 0.05 & -0.05 \\
\hline Classroom management & 1,403 & & & & & - & -0.01 & $0.14^{\star \star \star}$ & $0.06^{*}$ \\
\hline Cognitive activation & 1,403 & & & & & & - & $0.23^{\star \star \star}$ & $0.06^{*}$ \\
\hline Clarity of instruction & 1,404 & & & & & & & - & $0.06^{\star}$ \\
\hline Student-teacher relationship & 1,735 & & & & & & & & - \\
\hline
\end{tabular}

SES $=\%$ of students with a socioeconomically disadvantaged background; MIGR = \% of students with an immigrant status or migration background; Social utility value; Personal utility value; Workload; Classroom management; Cognitive activation; Clarity of instruction; Student-teacher Relationship. ${ }^{*} p<0.05$, ${ }^{* *} p<0.01,{ }^{* * *} p<0.001$.

of instruction, and student-teacher relationship) and interaction effects (social and personal utility value $\mathrm{x}$ workload and personal utility value $\times$ workload) were explored. Contrary to $\mathrm{H} 5$, no negative relations between workload and the teaching quality variables were found. In contrast, a positive relation was found for clarity of instruction $(\beta=0.05)$. In support of $\mathrm{H} 6$ we found social utility value to positively relate to all teaching quality variables (for clarity of instruction, $\beta=0.16$; classroom management, $\beta=0.13$; cognitive activation, $\beta=0.13$; studentteacher relationship, $\beta=0.10$ ). In addition, small effects were found for personal utility value on clarity of instruction $(\beta=0.08)$ and classroom management $(\beta=0.07)$. This supports $H 7$, stating no or small effects of personal utility value on teaching quality.

In contrast to $\mathrm{H} 8$, the moderation analysis showed no moderation effect on personal utility values. Unexpectedly and in contract to $\mathrm{H} 9$, an interaction between social utility value and workload on student-teacher relationship quality was found. Inspecting random slopes for low, medium and high levels of workload showed that the higher the workload, the more negative the relation between social utility value and studentteacher relationships.

Testing for random slopes for the lower level variables lacked support for cross-level interaction between the Level 2 (SES and MIGR) and Level 1 predictors (social and personal utility values and workload). Therefore, H10 and H11 were not supported.

\section{DISCUSSION}

Teaching quality is an important condition for learning and instruction (Jones and Jones, 2012). The present study focused on factors related to school population composition (i.e., SES and migration background), workload, and teachers' utility values (i.e., social and personal) on teaching quality (i.e., classroom management, cognitive activation, clarity of instruction, and positive student-teacher relationships). The Dutch TALIS-2018 data from secondary school teachers was used.

Firstly, in support of H1, it was found that teachers working at schools with a moderate (11-30\%) or high (> 30\%) share of students from a socioeconomically disadvantaged background reported spending less time and attention on a challenging and activating teaching style (i.e., cognitive activation) than their colleagues working at schools with a smaller share of low-SES students. Secondly, in line with $\mathrm{H} 2$ it was found that teachers working at schools with a moderate share (11-30\%) of students from a socioeconomically disadvantaged background provide more clarity of instruction than their colleagues working at schools with a smaller share of low-SES students. However, this effect was not found for the high SES group. Thirdly, in line with $\mathrm{H} 3$, teachers working at schools with high numbers of students with an immigrant status or migration background compared to their colleagues working at schools with lower numbers, indicated to have more negative relationships with their students. In contrast to $\mathrm{H} 4$, no association was found with classroom management.

Interestingly, we did not find a direct negative relationship between workload and teaching quality dimensions (no support for H5). Interpreted the most straightforward way, this could mean that teachers and their teaching quality are quite robust against workload. Research suggests that workload in itself may not be a negative factor for teacher quality. Indeed, a study by Johari et al. (2018) also found no relation between workload and job performance of teachers. On the contrary, Helms-Lorenz et al. (2015) investigated interventions in the induction programs of beginning teachers and found that workload was a positive predictor of teaching quality 3 years later. In line with this, Klassen and Chiu (2010) found that teachers who experienced more workload stress reported higher classroom management efficacy than their colleagues reporting lower stress levels. It seems that the headers in the Dutch media (i.e., Chaudron and Dujardin, 2019) saying that the educational quality suffers from workload asks for a more nuanced picture. We will try to present such a picture.

The Netherlands faces an increasing teacher shortage estimated to result in 1,263 full-time equivalents in 2024 (Vereninging van Scholen in het Voortgezet Onderwijs [VO RAAD], n.d.). These numbers are problematic for Dutch secondary education. The Dutch educational inspection explains that the quality of teaching and education suffers from teacher attrition due to the increasing workload (Inspectie van het Onderwijs, 2019). A shortage of teachers can result in fewer hours in the classroom due to a lack of qualified substitutes in case of 
teacher absence (e.g., sick leave) or in less quality of education due to un(der)qualified teachers in the classroom. Thus, while the present study found no relation between workload and teaching qualities in the current sample on the teacher level (all qualified teachers), educational quality, in general, is worsened by the overall teacher shortage and suboptimal solutions (unqualified teachers and canceled lessons).

In line with $\mathrm{H} 6$, the social utility values of teachers had a positive relationship with all teaching quality variables. In line with $\mathrm{H7}$, personal utility value had a small positive effects for classroom management and clarity of instruction. Several studies indicated that social utility values are associated with teaching quality (Richardson and Watt, 2014; Berger and Girardet, 2021; Parr et al., 2021). Results for personal utility values were mixed in prior research, showing positive associations with some outcomes and unrelated associations with other outcomes. Richardson and Watt (2014) found personal utility values unrelated to positive teaching behaviors. However, König and Rothland (2012) found that pre-service teachers' personal utility values are associated with the learning gain of pedagogical knowledge. We, therefore, expected that personal utility values would be unassociated or would show (small) positive effects. Unfortunately, little research can be found looking into teacher utility values and teaching qualities (as operationalized in the present study). However we can speculate that it might be related to the need for predictability and structure of the job, underlying personal utility value. As classroom management and clarity of instruction are more qualities focusing on the structure and rules (leading to a predictable classroom situation) during teaching, teachers are motivated by predictability and structure of their job, might hang on more to these qualities. More research is needed to see if these results can be replicated in future research.

We further examined associations and potential interaction effects between workload and utility values. Correlation analyses revealed that workload was positively associated with personal utility value, indicating that teachers scoring higher on this value also indicated to experience more workload. This can be explained by the idea that the concept of a steady job with fixed hours that fits well with the teachers' personal life (e.g., holidays, part-time work; Watt and Richardson, 2007) is jeopardized by increasing workload. In contrast to H8, workload did not moderate the effect of personality utility values on teaching quality. However, we did find a unexpected (with regard to H9) interaction effect between social utility value and workload. Specifically, it was found that the relation between social utility value and student-teacher relations became more negative with increasing workload. In trying to explain this effect, we tried to look closer in what kind of workload has increased in the last decade(s). McGrath-Champ et al. (2018) point out that specifically the increased administrative load of teachers poses a serious threat to their original profession (teaching quality and student learning). We assume that especially for teachers with a high social utility value, the quality of student-teacher relationships might suffer from increasing administrative tasks.

No cross-level interactions were found which means that we found no support for $\mathrm{H} 10$ and H11. This indicates that the relation between social and personal utility value and workload did not differ depending on the share of low-SES students and (or) students with a migrant background.

In the present study, we examined the relationships between school composition, workload, utility values, and teaching quality using the Dutch TALIS data. These concepts are extensively theorized in international research, and insights into their relationships are interesting for an international audience. However, the Dutch educational system and the migration histories of Dutch pupils and their socioeconomic situation may lead to a specific set of results for the Netherlands. Even though our results do not seem to indicate such specificity, as most of our hypotheses can be confirmed, it is important to replicate the analyses in other national TALIS datasets to find out more about the role of specific educational systems and school population compositions.

School population composition measures for SES and migration background were at the school level and not class level. We acknowledge that shares of students with a migrant background and socioeconomically disadvantaged background at the school level may differ from the shares that teachers see in a specific classroom. TALIS does provide data on the teacher level on an estimate of SES and migration backgrounds in a specific classroom (i.e., "the first class you taught after 11 a.m. last Tuesday”). However, because all teachers teach multiple classes, these shares differ between classes. We felt that the average school-level report represent the experience of teachers on shares of low-SES and migration background students better than asking for a random class, hence the choice to look at SES and migration background at school level.

Another point for discussion is that the intraclass correlations (ICCs, see Table 2) are quite low for three of the four dependent variables (i.e., < 5\%). The decision to take a multilevel approach, despite low ICCs was based on a significantly better fit for the model when variances within and between clusters on the dependent variables are accounted for compared to the model in which no variance between clusters is assumed.

Moreover, the present study solely looked at the selfreports of teachers. This can be problematic because only the teacher's perspective is considered. Krammer et al. (2019) showed strong measurement invariance when comparing the teachers' ratings to that of their students. In addition, students have an advantage over the teacher when observing lessons because they are not teaching (i.e., teachers are multitasking and might be under pressure when confronted with high social density, unstructured problems, dynamic situations, and multiple demands; Scherzinger and Wettstein, 2019). Moreover, in line with Krammer et al. (2019), Scherzinger and Wettstein (2019) also showed discrepancies between teacher and student judgments of teaching quality, so the validity of only using teacher ratings can be debated. Another issue with using one method and one source of information is that found (cor)relations may be partially due to the single method (i.e., common method bias; Podsakoff et al., 2003). Future research is needed to find out whether current findings can be supported by other methods, such as looking at formal assessments of teachers' performance or classroom observations. 


\section{CONCLUSION}

In conclusion, our main finding is that teachers seem to adapt their teaching quality to their teaching population. On the one hand, this is positive as students have individual needs that can be fulfilled in this manner. However, if incorrect preconceptions cause these adaptations, this can negatively affect students' outcomes (Hornstra et al., 2015; Agirdag, 2018). Indeed in the present study, we confirm earlier findings (Willms, 2010; Rjosk et al., 2014). Teachers rely less on cognitive activation and more on clarification when working at schools with a fair number of students with socioeconomically disadvantaged backgrounds. Thus, schools, where the socioeconomically disadvantaged background of students is more pronounced, might need to focus on the (pre)conceptions of the teachers about students with socioeconomically disadvantaged backgrounds and, when needed, align these (pre)conceptions correctly with the cognitive abilities of these students.

In addition, we also confirm earlier findings (e.g., Thijs et al., 2012) that ethnic diversity is a challenge for the quality of the relationship between teachers and students. More specifically, our results showed that teachers in more ethnically diverse schools reported a lower studentteacher relationship quality, reporting these relationships as less warm, caring, and emotionally supportive. Teachers' misconceptions about students' needs could partially explain this negative association. Hornstra et al. (2015) showed that teachers are less supportive of students' autonomy needs of at-risk students because they believe that students with low-SES, low ability levels, or an ethnic minority background need more teacher control. However, students' autonomy needs should be equally supported (Patall and Zambrano, 2019; Archambault et al., 2020). Therefore, more research is needed on the factors influencing their beliefs about students' SES and migration background. In addition, Wubbels et al. (2006) and Severiens et al. (2014) underscore the importance of the interpersonal competence of teachers in ethnically diverse classrooms. Our findings have implications for the focus of teacher training and professional development activities offered. Ethnically diverse schools might offer more interpersonal training focusing on diversity. Another way to improve teaching quality in ethnically diverse schools is to invest more in culturally responsive teaching (Gay, 2002). Culturally responsive teaching uses ethnically diverse students' cultural characteristics, experiences, and perspectives to teach more effectively. This way of teaching aligns well with the concept of autonomysupportive teaching, in which teachers can take the perspective of their students (Patall and Zambrano, 2019), which is considered an aspect of good classroom management (Berger and Girardet, 2021).

In line with prior research (Richardson and Watt, 2014; Girardet and Berger, 2018; Berger and Girardet, 2021), social utility value toward teaching was related to more teaching qualities than personal utility value. This indicates that it is important to promote (pre-service) teachers' motivation to contribute to society and enhance social equity. This conclusion should be interpreted with caution as the present study limited teaching quality by the four components analyzed (i.e., classroom management, cognitive activation, clarity of instruction, and student-teacher relationships). However, we defined the chosen teaching quality components based on recurrent elements we found in our literature research described in the introduction.

In sum, the current study suggests that teachers' teaching qualities are adapted when dealing with students from socioeconomically disadvantaged backgrounds and or children with an immigrant status or migration background. Although SES and migration are correlated, different relations with teaching qualities are found in the multilevel analysis. While SES is mainly related to the cognitive aspects of teaching quality, is migration background more related to social aspects of teaching quality. Hence the main conclusion from this study is that to work on effective teaching by improving teaching quality, SES and migration need different approaches.

\section{DATA AVAILABILITY STATEMENT}

Publicly available datasets were analyzed in this study. This data can be found here: https://www.oecd.org/education/talis/talis2018-data.htm.

\section{ETHICS STATEMENT}

The studies involving human participants were reviewed and approved by the OECD which was responsible for the ethical approval. The patients/participants provided their written informed consent to participate in this study.

\section{AUTHOR CONTRIBUTIONS}

KO was part of the Dutch TALIS 2018 consortium together with MM and SS that gathered, analyzed, and reported on the Dutch TALIS 2018 data. KX was a consultant for the analyses for the study. LW was closely collaborating with $\mathrm{KO}$ in writing the manuscript. All authors contributed to the article and approved the submitted version.

\section{FUNDING}

This work was supported by a grant from the Dutch Ministry of Education, NRO number 504.16.385/374. The Erasmus Open Access Fonds will pay the listed article processing fee should the manuscript be accepted for publication. 


\section{REFERENCES}

Aelterman, N., Vansteenkiste, M., Haerens, L., Soenens, B., Fontaine, J. R. J., and Reeve, J. (2019). Toward an integrative and fine-grained insight in motivating and demotivating teaching: the merits of a circumplex approach. J. Educ. Psychol. 111, 497-521. doi: 10.1037/edu0000293

Agirdag, O. (2018). The impact of school SES composition on science achievement and achievement growth: mediating role of teachers' teachability culture. Educ. Res. Eval. 24, 264-276. doi: 10.1080/13803611.2018.1550838

Amitai, A., and Van Houtte, M. (2022). Being pushed out of the career: former teachers' reasons for leaving the profession. Teach. Teach. Educ. 110:103540. doi: 10.1016/j.tate.2021.103540

Archambault, I., Pascal, S., Tardif-Grenier, K., Dupéré, V., Janosz, M., Parent, S., et al. (2020). The contribution of teacher structure, involvement, and autonomy support on student engagement in low-income elementary schools. Teach. Teach. 26, 428-446. doi: 10.1080/13540602.2020.1863208

Baumert, J., Kunter, M., Blum, W., Brunner, M., Voss, T., Jordan, A., et al. (2010). Teachers' mathematical knowledge, cognitive activation in the classroom, and student progress. Am. Educ. Res. J. 47, 133-180. doi: 10.3102/ 0002831209345157

Berger, J.-L., and Girardet, C. (2021). Vocational teachers' classroom management style: the role of motivation to teach and sense of responsibility. Eur. J. Teach. Educ. 44, 200-216. doi: 10.1080/02619768.2020.1764930

Breslow, N. E., and Day, N. E. (1987). Statistical methods in cancer research Volume II. The design and analysis of cohort studies. Lyon: International Agency for Research on Cancer.

Bruinsma, M., and Jansen, E. P. (2010). Is the motivation to become a teacher related to pre-service teachers' intentions to remain in the profession?. Eur. J. Teach. Educ. 33, 185-200. doi: 10.1080/02619760903512927

Centraal Bureau voor de Statistiek [CBS] (2020). Jaarrapport Integratie. Available online at: https://longreads.cbs.nl/integratie-2020/ (accessed November 14, 2021).

Chaudron, J., and Dujardin, A. (2019). Van basisschool tot Universiteit, de werkdruk is totaal uit de klauwen gelopen. Jacob Bontiusplaats: Trouw.

Den Brok, P., Wubbels, T., and Van Tartwijk, J. (2017). Exploring beginning teachers' attrition in the Netherlands. Teach. Teach. 23, 881-895. doi: 10.1080/ 13540602.2017.1360859

Deng, L., and Chan, W. (2017). Testing the difference between reliability coefficients alpha and omega. Educ. Psychol. Meas. 77, 185-203. doi: 10.1177/ 0013164416658325

Dube-Xaba, Z., and Makae, M. P. (2022). Assuring quality of school-based assessment: the perspectives of heads of department in moderating tourism tasks. Qual. Assur. Educ. 30, 87-101. doi: 10.1108/QAE-04-2021-0049

Fauth, B., Decristan, J., Decker, A.-T., Büttner, G., Hardy, I., Klieme, E., et al. (2019). The effect of teacher competence on student outcomes in elementary science education: the mediating role of teaching quality. Teach. Teach. Educ. 86:102882. doi: $10.1016 /$ j.tate.2019.102882

Gay, G. (2002). Preparing for culturally responsive teaching. J. Teach. Educ. 53, $106-116$.

Geerlings, J., Thijs, J., and Verkuyten, M. (2018). Teaching in ethnically diverse classrooms: examining individual differences in teacher self-efficacy. J. Sch. Psychol. 67, 134-147. doi: 10.1016/j.jsp.2017.12.001

Giersch, J. (2016). A test of personal and social utility values and the appeal of a career in teaching. Educ. Res. Policy Pract. 15, 163-173. doi: 10.1007/s10671016-9194-7

Girardet, C., and Berger, J.-L. (2018). Factors influencing the evolution of vocational teachers' beliefs and practices related to classroom management during teacher education. Aust. J. Teach. Educ. 43, 138-158. doi: 10.14221/ajte. $2018 \mathrm{v} 43 \mathrm{n} 4.8$

Gustafsson, J. E., Nilsen, T., and Hansen, K. Y. (2018). School characteristics moderating the relation between student socioeconomic status and mathematics achievement in grade 8. Evidence from 50 countries in TIMSS 2011. Stud. Educ. Eval. 57, 16-30. doi: 10.1016/j.stueduc.2016. 09.004

Harmsen, R., Helms-Lorenz, M., Maulana, R., Van Veen, K., and Van Veldhoven, M. (2019). Measuring general and specific stress causes and stress responses among beginning secondary school teachers in the Netherlands. Int. J. Res. Method Educ. 42, 91-108. doi: 10.1080/1743727X.2018.1462313
Heisig, J. P., and Schaeffer, M. (2019). Why you should always include a random slope for the lower-level variable involved in a cross-level interaction. Eur. Soc. Rev. 35, 258-279. doi: 10.1093/esr/jcy053

Helms-Lorenz, M., Van de Grift, W., and Maulana, R. (2015). Longitudinal effects of induction on teaching skills and attrition rates of beginning teachers. Sch. Eff. Sch. Improv. 27, 178-204. doi: 10.1080/09243453.2015.1035731

Higgins, S., Major, L. E., and Coe, R. (2014). What makes great teaching. Professional Voice; What Works (and What Doesn't). London: Sutton Trust.

Hornstra, L., Mansfield, C., Van der Veen, I., Peetsma, T., and Volman, M. (2015). Motivational teacher strategies: the role of beliefs and contextual factors. Learn. Environ. Res. 18, 363-392. doi: 10.1007/s10984-015-9189-y

Huyghebaert, T., Gillet, N., Beltou, N., Tellier, F., and Fouquereau, E. (2018), Effects of workload on teachers' functioning: a moderated mediation model including sleep problems and overcommitment. Stress Health 34, 601-611. doi: $10.1002 /$ smi.2820

Inspectie van het Onderwijs (2019). Technisch rapport leraren en lerarentekort [Technical report teachers and teacher shortage]. Netherlands: Inspectie van het Onderwijs.

Jennissen, R., Engbersen, G., Bokhorst, M., and Bovens, M. (2018). De nieuwe verscheidenheid. Toenemende diversiteit naar herkomst in Nederland. Netherlands: Wetenschappelijke Raad voor het Regeringsbeleid.

Johari, J., Tan, F. Y., Iwani, Z., and Zulkarnain, T. (2018). Autonomy, workload, work-life balance and job performance among teachers. Int. J. Educ. Manag. 32, 107-120. doi: 10.1108/IJEM-10-2016-0226

Jones, V. F., and Jones, L. S. (2012). Comprehensive Classroom Management, Creating Communities of Support and Solving Problems, 10th Edn. Upper Saddle River: Pearson.

Klassen, R. M., and Chiu, M. M. (2010). Effects on teachers' self-efficacy and job satisfaction: teacher gender, years of experience, and job stress. J. Educ. Psychology102, 741-756. doi: 10.1037/a0019237

Klieme, E. (2013). "The role of large-scale assessments in research on educational effectiveness and school development," in The Role of International Large-Scale Assessments: Perspectives from Technology, Economy, and Educational Research, eds M. von Davier, E. Gonzalez, I. Kirsch, and K. Yamamoto (Dordrecht: Springer), 115-147. doi: 10.1007/978-94-007-4629-9

Klieme, E., Pauli, C., and Reusser, K. (2009). "The Pythagoras study: Investigating effects of teaching and learning in Swiss and German mathematics classrooms," in The Power of Video Studies in Investigating Teaching and Learning in the Classroom, eds T. Janik and T. Seidel (Münster: Waxmann), 137-160.

König, J., and Rothland, M. (2012). Motivations for choosing teaching as a career: effects on general pedagogical knowledge during initial teacher education. Asia Pac. J. Teach. Educ. 40, 289-315. doi: 10.1080/1359866X.2012. 700045

Korpershoek, H., Harms, T., De Boer, H., Van Kuijk, M., and Doolaard, S. (2016). A meta-analysis of the effects of classroom management strategies and classroom management programs on students' academic, behavioral, emotional, and motivational outcomes. Rev. Educ. Res. 86, 643-680. doi: 10. 3102/0034654315626799

Krammer, G., Pflanzl, B., and Mayr, J. (2019). Using students' feedback for teacher education: measurement invariance across pre-service teacher-rated and student-rated aspects of quality of teaching. Assess. Eval. High. Educ. 44, 596-609. doi: 10.1080/02602938.2018.1525338

Krieg, J. M. (2006). Teacher quality and attrition. Econ. Educ. Rev. 25, 13-27. doi: 10.1016/j.econedurev.2004.09.004

Lazarides, R., Fauth, B., Gaspard, H., and Göllner, R. (2021). Teacher self-efficacy and enthusiasm: relations to changes in perceived teaching quality at the beginning of secondary education. Learn. Instruct. 73:101435. doi: 10.1016/j. learninstruc.2020.101435

Liu, S., Keeley, J. W., and Sui, Y. (2020). Multilevel of factors influencing teacher job satisfaction in China: evidence from the TALIS 2018. Educ. Stud. doi: 10.1080/03055698.2020.1837615

Maulana, R., Opdenakker, M. C., and Bosker, R. (2016). Teachers' instructional behaviors as important predictors of academic motivation: changes and links across the school year. Learn. Individ. Differ. 50, 147-156. doi: 10.1016/j.lindif. 2016.07.019

McGrath-Champ, S., Wilson, R., Stacey, M., and Fitzgerald, S. (2018). Understanding work in schools: The foundation for teaching and learning. 2018 Report to the NSW Teachers Federation. Sydney: NSW Teachers Federation. 
Nuffic De Nederlandse organisatie voor internationalisering in onderwijs. Available online at: https://www.nuffic.nl/en/education-systems/netherlands/ primary-and-secondary-education (accessed February 9, 2022).

O’Brien, L. M., and Schillaci, M. (2002). Why do I want to teach, anyway? Utilizing autobiography in teacher education. Teach. Educ. 13, 25-40. doi: 10.1080/ 1047210120128564

Organisation for Economic Co-Operation and Development [OECD] (2019). TALIS 2018 Technical Report. Paris: OECD Publishing.

Parkhouse, H., Lu, C. Y., and Massaro, V. R. (2019). Multicultural education professional development: a review of the literature. Rev. Educ. Res. 89, $416-458$.

Parr, A., Gladstone, J., Rosenzweig, E., and Wang, M.-T. (2021). Why do I teach? A mixed-methods study of in-service teachers' motivations, autonomy-supportive instructions, and emotions. Teach. Teach. Educ. 98:103228. doi: 10.1016/j.tate. 2020.103228

Patall, E. A., and Zambrano, J. (2019). Facilitating student outcomes by supporting autonomy: implications for practice and policy. Policy Insights Behav. Brain Sci. 6, 115-122. doi: 10.1177/2372732219862572

Payne, C. M. (2014). So much reform, so little change. The persistence of failure in urban schools. Cambridge: Harvard University Press.

Podsakoff, P. M., MacKenzie, S. B., Lee, J.-Y., and Podsakoff, N. P. (2003). Common method biases in behavioral research: a critical review of the literature and recommended remedies. J. Appl. Psychol. 88, 879-903. doi: 10.1037/0021-9010. 88.5.879

Richardson, P. W., and Watt, H. G. (2014). "Why people choose teaching as a career: An expectancy-value approach to understanding teacher motivation," in Teacher Motivation: Theory and Practice, eds P. W. Richardson, S. A. Karabenick, and H. M. G. Watt (New York: Routledge), 3-19. doi: 10.4324/ 9780203119273-1

Rjosk, C., Richter, D., Hochweber, J., Lüdtke, O., Klieme, E., and Stanat, P. (2014). Socioeconomic and language minority classroom composition and individual reading achievement: the mediating role of instructional quality. Learn. Instr. 32, 63-72. doi: 10.1016/j.learninstruc.2014.01.007

Sapulete, S., De Wilde, P., Ouwehand, K., and Van der Boom, E. (2018). Teaching and Learning International Survey (TALIS) 2018. Nationaal rapport voortgezet onderwijs. [National report secondary education]. Netherlands: Rijksoverheid.

Scheerens, J. (1990). School effectiveness research and the development of process indicators for school functioning. Sch. Eff. Sch. Improv. J. 1, 61-80. doi: 10.1080/ 0924345900010106

Scheerens, J. (2000). Improving school effectiveness. Fundamentals of Educational Planning (No. 68). Paris: United Nations Educational, Scientific and Cultural Organization.

Scherzinger, M., and Wettstein, A. (2019). Classroom disruptions, the teacher-student relationship and classroom management from the perspective of teachers, students and external observers: a multimethod approach. Learn. Environ. Res. 22, 101-116. doi: 10.1007/s10984-0189269-x
Severiens, S., Wolff, R., and Van Herpen, S. (2014). Teaching for diversity: a literature overview and an analysis of the curriculum of a teacher training college. Eur. J. Teach. Educ. 37, 295-311. doi: 10.1080/02619768.2013.845166

Thijs, J., Westhof, S., and Koomen, H. (2012). Ethnics incongruence and the student-teacher relationship: the perspective of ethnic majority teachers. J. Sch. Psychol. 50, 257-273. doi: 10.1016/j.jsp.2011.09.004

Tielman, K., Wesselink, R., and Den Brok, P. (2021). Tensions experienced by teachers of Dutch culturally diverse senior secondary vocational education and training: an exploratory study. Int. J. Train. Dev. 1-18. doi: 10.1111/ijtd.12238

Traag, T., (2018). Statistische Trends: Leerkrachten in het Basisonderwijs. Netherlands: Centraal Bureau voor de Statistiek.

Vereninging van Scholen in het Voortgezet Onderwijs [VO RAAD] (n.d.). Lerarentekort. Available online at: https:/www.vo-raad.nl/themas/ ontwikkeling-leraren/onderwerpen/lerarentekort-e38d9309-3dfb-4caf990a-1c0ad2d0136d (accessed November 15, 2021)

Watt, H. M., and Richardson, P. W. (2007). Motivational factors influencing teaching as a career choice: development and validation of the FIT-Choice scale. J. Exp. Educ. 75, 167-202. doi: 10.1016/j.tate.2012.03.003

Watt, H. M., and Richardson, P. W. (2012). An introduction to teaching motivations in different countries: comparisons using the FIT-Choice scale. Asia Pac. J. Teach. Educ. 40, 185-197. doi: 10.1080/1359866X.2012.700049

Wentzel, K. R. (2009). "Students' relationships with teachers as motivation contexts," in Handbook of Motivation in School, eds K. Wentzel and A. Wigfield (Mahwah: Erlbaum), 301-322.

Willms, J. D. (2010). School composition and contextual effects on student outcomes. Teach. Coll. Rec. 112, 1008-1037. doi: 10.1177/016146811011200408

Wubbels, T., Den Brok, P., Veldman, I., and Van Tartwijk, J. (2006). Teacher interpersonal competence for Dutch secondary multicultural classrooms. Teach. Teach. Theor. Pract. 12, 407-433. doi: 10.1080/1315060060061126

Conflict of Interest: The authors declare that the research was conducted in the absence of any commercial or financial relationships that could be construed as a potential conflict of interest.

Publisher's Note: All claims expressed in this article are solely those of the authors and do not necessarily represent those of their affiliated organizations, or those of the publisher, the editors and the reviewers. Any product that may be evaluated in this article, or claim that may be made by its manufacturer, is not guaranteed or endorsed by the publisher.

Copyright (C) 2022 Ouwehand, Xu, Meeuwisse, Severiens and Wijnia. This is an open-access article distributed under the terms of the Creative Commons Attribution License (CC BY). The use, distribution or reproduction in other forums is permitted, provided the original author(s) and the copyright owner(s) are credited and that the original publication in this journal is cited, in accordance with accepted academic practice. No use, distribution or reproduction is permitted which does not comply with these terms. 


\section{APPENDIX}

\section{Items of All Scales Used in the Analyses \\ Social Utility Motivation to Teach (T3SOCUT)}

TT3G07: How important were the following for you to become a teacher?

Response options: "Not important at all" (1), "Of low importance" (2), "Of moderate importance" (3), "Of high importance" (4). TT3G07E Teaching allowed me to influence the development of children and young people.

TT3G07F Teaching allowed me to benefit the socially disadvantaged.

TT3G07G Teaching allowed me to provide a contribution to society.

\section{Personal Utility Motivation to Teach (T3PERUT)}

TT3G07: How important were the following for you to become a teacher?

Response options: "Not important at all" (1), "Of low importance" (2), "of moderate importance" (3), "Of high importance" (4).

TT3G07A Teaching offered a steady career path.

TT3G07B Teaching provided a reliable income.

TT3G07C Teaching was a secure job.

TT3G07D The teaching schedule (e.g., hours, holidays, part-time positions) fit with responsibilities in my personal life.

\section{Workload Stress (T3WLOAD)}

TT3G52: Thinking about your job at this school, to what extent are the following sources of stress in your work?

Response options: "Not at all” (1), “To some extent" (2), "Quite a bit" (3), “A lot" (4).

TT3G52A Having too much lesson preparation.

TT3G52B Having too many lessons to teach.

TT3G52C Having too much marking.

TT3G52D Having too much administrative work to do (e.g., filling out forms).

TT3G52E Having extra duties due to absent teachers.

\section{Clarity of Instruction (T3CLAIN)}

TT3G42: Thinking about your teaching in the <target class $>$, how often do you do the following?

Response options: "Never or almost never" (1), "Occasionally" (2), "Frequently" (3), "Always" (4).

TT3G42A I present a summary of recently learned content.

TT3G42B I set goals at the beginning of instruction.

TT3G42C I explain what I expect the students to learn.

TT3G42D I explain how new and old topics are related.

\section{Classroom Management (T3CLASM)}

TT3G42: Thinking about your teaching in the <target class $>$, how often do you do the following? Response options: "Never or almost never" (1), "Occasionally" (2), "Frequently" (3), "Always" (4). TT3G42I I tell students to follow classroom rules.

TT3G42J I tell students to listen to what I say.

TT3G42K I calm students who are disruptive.

TT3G42L When the lesson begins, I tell students to quieten down quickly.

\section{Cognitive Activation (T3COGAC)}

TT3G42: Thinking about your teaching in the $<$ target class $>$, how often do you do the following?

Response options: "Never or almost never" (1), "Occasionally" (2), "Frequently" (3), "Always" (4).

TT3G42E I present tasks for which there is no obvious solution.

TT3G42F I give tasks that require students to think critically.

TT3G42G I have students work in small groups to come up with a joint solution to a problem or task.

TT3G42H I ask students to decide on their own procedures for solving complex tasks.

\section{Student-Teacher Relations (T3STUD)}

TT3G49: How strongly do you agree or disagree with the following statements about what happens in this school?

Response options: "Strongly disagree" (1), "Disagree" (2), "Agree" (3), "Strongly agree" (4).

TT3G49A Teachers and students usually get on well with each other.

TT3G49B Most teachers believe that the students' well-being is important.

TT3G49C Most teachers are interested in what students have to say.

TT3G49D If a student needs extra assistance, the school provides it. 